\title{
PERSEPSI MASYARAKAT TERHADAP DAMPAK KONVERSI LAHAN HUTAN MENJADI PERKEBUNAN KELAPA SAWIT PT. BUMI PRATAMA KHATULISTIWA DI DESA SUNGAI ENAU KECAMATAN KUALA MANDOR B KABUPATEN KUBU RAYA
}

\author{
(Community Perception of the Impact of Forest Conversion to Plantation of Palm Oil PT. Bumi \\ Pratama Khatulistiwa in the Sungai Enau VillageKuala Mandor B Subdistrict Kubu Raya District)
}

\section{Cici Paramida, Emi Roslinda, Evy Wardenaar}

Fakultas Kehutanan Universitas Tanjungpura Jl. Daya Nasional, Pontianak 78124

Email : cicimida21@gmail.com

\begin{abstract}
The conversion of forest land into oil palm plantations of PT. Bumi Pratama Khatulistiwa in Sungai Enau village Kuala mandor B sub-district Kubu Raya district has been around for a long time. The study of community perceptions of the impact of the conversion of forest land into oil palm plantations in the Sungai Enau village of Kuala mandor Bsubdistrict Kubu Raya district has not been carried out so it is necessary to study the impact of the conversion of forest land into oil palm plantations. The purpose of this study is to examine the community perceptions of the impact of forest land into oil palm plantations and examine the factors that influence community perceptions of Sungai Enau village on the impact of the conversion of forest land into oil palm plantations. This study used a purposive sampling method. Data analysis was carried out by descriptive analysis and inferential analysis. The results showed that community's perception of the impact of the conversion of forest land into that plantations in the Sungai Enau village, Kuala mandor B subdistrict, Kubu Raya district, which had a neutral perception with a frequency value of $62.83 \%$, there is a positive and significant relationship between the level of knowledge and people perceptions on the impact of the conversion of forest land into oil palm plantations, and there is a positive and insignificant relationship between the level of income and cosmopolitan levels with the community perception of the impact of converting forest land into oil palm plantations in Sungai Enau village Kuala Mandor B subdistrict Kubu Raya district.
\end{abstract}

Keywords : Conversion of forest land, community, impacts, oil palm and perception

\section{PENDAHULUAN}

Konversi lahan hutan adalah perubahan fungsi pokok hutan menjadi kawasan non hutan seperti, pemukiman, areal pertanian dan perkebunan. Menurut Lort dan Clay (2011) ekspansi kelapa sawit adalah salah satu ancaman bagi habitat hewan yang teranam punah kareana kelapa sawit merupakan penyebab yang paling signifikan dari fragmentasi habitat di Kalimantan dan
Sumatra. Departemen Kehutanan semakin banyak mengeluarkan izin alih fungsi kawasan hutan untuk perkebunan seluas 6,7 juta ha sampai dengan tahun 1997. Konversi lahan hutan untuk penggunaan lain sudah terbukti sebagai ancaman terhadap keberadaan wilayah hutan. Kebakaran hutan sering terjadi sejak praktek pembakaran hutan digunakan untuk membuka lahan perkebunan (Murniati et al. 2008). 
Konversi lahan hutan menjadi perkebunan kelapa sawit telah ada sejak tahun 1996 di Desa Sungai Enau dan sampai saat ini belum diketahuinya persepsi masyarakat terhadap konversi lahan menjadi perkebunan kelapa sawit di Desa Sungai Enau Kecamatan Kuala Mandor B Kabupaten Kubu Raya, pentingnya persepsi masyarakat terhadap konversi lahan hutan menjadi perkebunan kelapa sawit agar masyarakat menyadari dampak nyata terhadap lingkungan dimasyarakat walaupun didalam perekonomian masyarakat menjadi meningkat karena tersedianya lapangan pekerjaan.

Konversi lahan hutan menjadi perkebunan kelapa sawit mempunyai dampak yang positif dan negatif pada masyarakat Desa Sungai Enau. Dampak positif setelah adanya perkebunan kelapa sawit PT. Bumi Pratama Khatulistiwa terhadap perekonomian masyarakat di Desa Sungai Enau, perkebunan kelapa sawit membawa dampak langsung terhadap peningkatan pendapatan di Kecamatan Kuala Mandor B khususnya pada masyarakat Desa Sungai Enau. Dengan adanya perkebunan kelapa sawit juga membuka lapangan kerja baru bagi masyarakat yang tidak memiliki pekerjaan, ini merupakan keuntungan tersendiri yang dihasilkan dari adanya perkebunan kelapa sawit, dampak ekonomi dari konversi lahan hutan menjadi perkebunan kelapa sawit telah berupaya mempercepat peningkatan investasi perekomian yang beragam (Syahza et al. 2011). Pembangunan perkebunan kelapa sawit juga berdampak terhadap perubahan sosial masyarakat terhadap tingkat pendidikan dan kesehatan masyarakat menjadi lebih baik, angka putus sekolah berkurang dan asupan gizi bagi anak-anak dapat dipenuhi, sehingga dari segi perekonomian masyarakat menjadi meningkat dan pola kehidupan mereka tentu mengalami perubahan. Namun dampak negatif yang ditimbulkan dari konversi lahan hutan menjadi perkebunan kelapa sawit yaitu masyarakat kehilangan lahan dan kebun karena sebagian masyarakat menjual lahan dan kebun mereka kepada pemilik perkebunan kelapa sawit dan timbulnya pencemaran (air dan udara). Penyataaan ini sejalan dengan penelitian (Yani,2011) akibat dari ekspansi perkebunan kelapa sawit yang dilakukan dengan melalui konversi hutan alam, akan merusak habitat hutan dan merubah lanskap hutan alam serta merusak kondisi daerah aliran sungai (DAS).

\section{METODE PENELITIAN}

Penelitian ini dilaksanakan di Desa Sungai Enau Kecamatan Kuala Mandor B Kabupaten Kubu Raya, pengambilan data dilaksanakan selama \pm 3 minggupada tanggal 25 Maret-April 2019, dilakukan dengan teknik wawancara langsung menggunakan alat bantu kuisioner. Metode pengambilan sampel responden pada penelitian ini adalah dengan teknik purposive sampling, penentuan jumlah responden menggunakan rumus slovin (Silaen dan Widiyono. 2013) seperti berikut:

$$
\mathrm{n}=\frac{\mathrm{N}}{1+\mathrm{Ne}^{2}}
$$


Dimana:

$\mathrm{n}=$ Jumlah Sampel responden

$\mathrm{N}=$ Jumlah Populasi responden

$\mathrm{e}=$ Persentase ketidak telitian yang masih dapat di tolerir (20\%). adalah (1) KK di Desa Sungai Enau yaitu dusun (Sunge ano, Saga, Ampaning, Jaya dan Padi jaya), (2) lama berdomisili minimal 5 tahun, (3) Usia minimal 17 tahun (4) sehat jasmani dan rohani. Peta lokasi penelitian pada gambar dibawah ini :

Kriteria masyarakat yang dijadikan responden secara purposive sampling

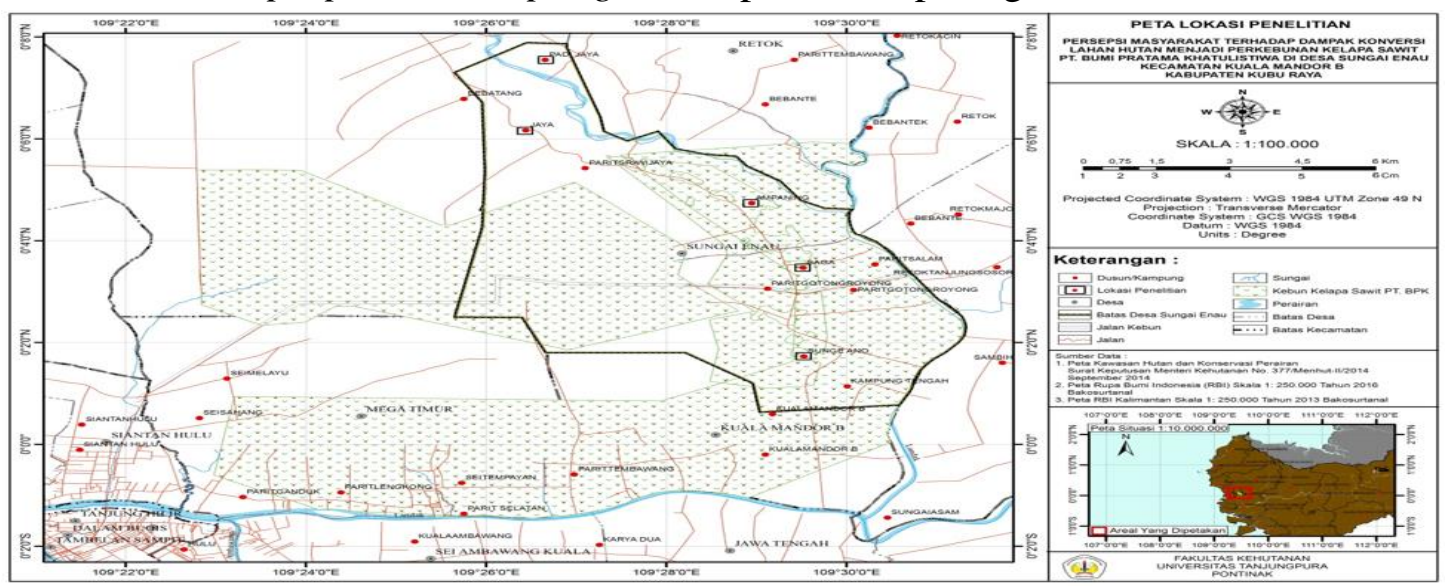

Gambar. 1 Peta Lokasi Peneliti (Map of Research Location)

Berdasarkan perhitungan rumus slovin didapat total responden 113 kepala keluarga pada Tabel berikut ini :

Tabel 1. Jumlah Populasi Dan Sampel Responden Penelitian (Total Population and Sample of Respondents Research)

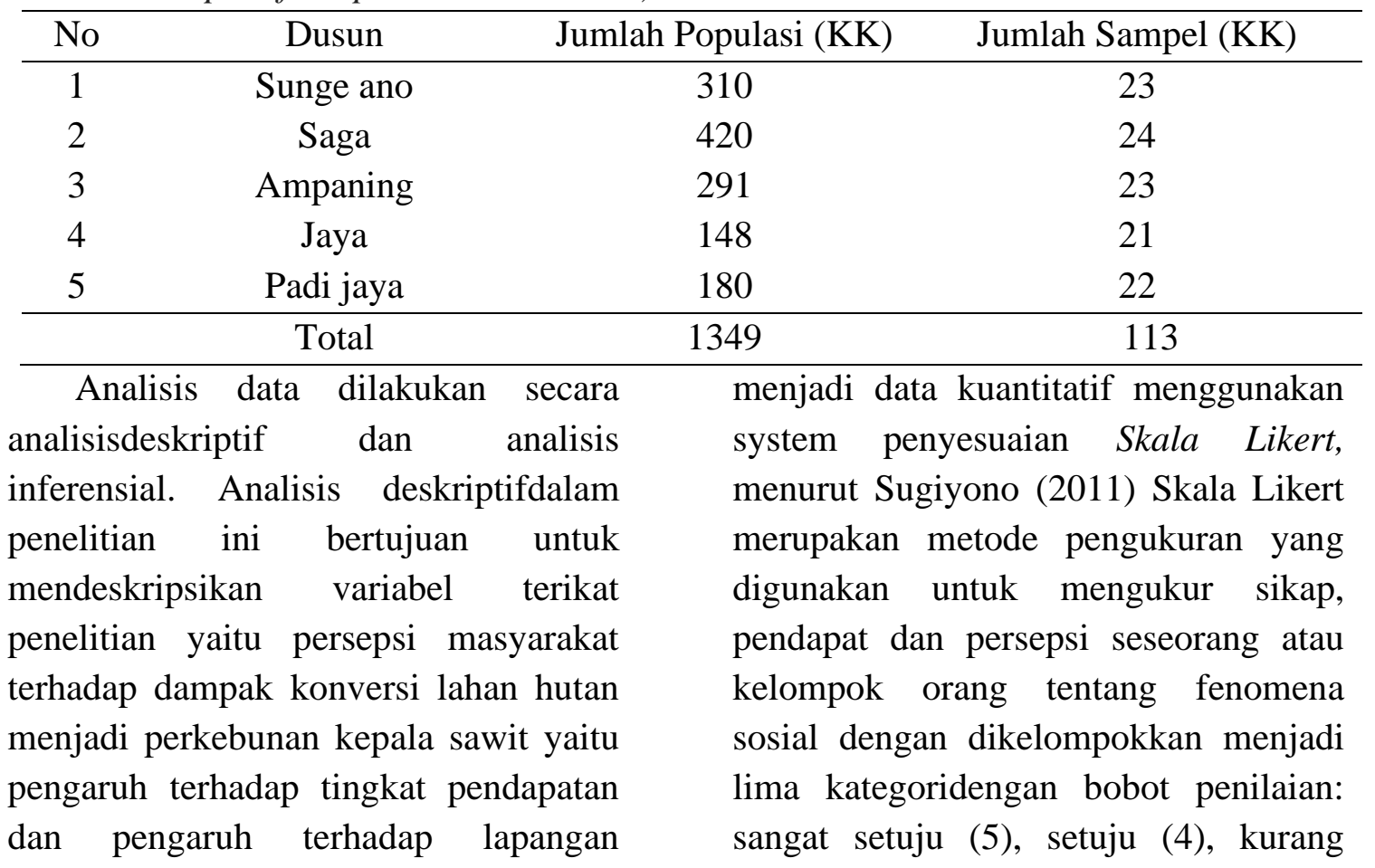

perkerjaan. Data kualitatif dirubah 
setuju (3), tidak setuju (2), dan sangat tidak setuju (1).

Berdasarkan total skor dari nilai bobot masing-masing item pertanyaan selanjutnya dari lima kategori tersebut dirubah menjadi tiga kategori (positif, netral dan negatif). Dengan menggunakamn rumus Standar Deviasi dengan bantuan komputer (Microsoft Excel) sebagai berikut :

$$
\mathrm{SD}=\sqrt{\frac{n \sum x i^{2}-\left(\sum x i^{2}\right)}{n(n-1)}}
$$

Keterangan :

$\mathrm{SD}=$ Standar Deviasi

$\mathrm{n}=$ Jumlah Responden

$\mathrm{xi}=$ Nilai $\mathrm{x}$ ke $\mathrm{i}$

$\mathrm{x}=$ Rata- rata

Dengan ketentuan sebagai berikut :

- Positif, jika persepsi masyarakat $>\mathrm{X}+\mathrm{SD}$

- Netral, jika persepsi masyarakat $\mathrm{x}$ $\mathrm{SD}-\mathrm{x}+\mathrm{SD}$

- Negatif, jika persepsi masyarakat $<\mathrm{x}-\mathrm{SD}$

Analisis data dilakukan secara deskriptif dan analisis inferensial. Analisis deskriptif persepsi dilakukan dengan analisis statistik non parametrik chi kuadrat $\left(X^{2}\right)$. Menurut Sugiyono (2011) Chi-kuadrat $\left(X^{2}\right)$ satu sampel teknik statistik yang digunakan untuk menguji hipotesis deskriptif bila dalam populasi terdiri atas dua atau lebih kelas kategori, data berbentuk nominal dan sampelnya besar, untuk melihat tingkat persepsi masyarakat terhadap konversi lahan hutan menjadi perkebunan kelapa sawit dengan menggunakan rumus chi kuadrat sebagai berikut:
$X^{2}=\sum \frac{\left(f_{o-} f_{h}\right)^{2}}{f_{h}}$

Dimana :

$X^{2}=$ chi-kuadrat

$f_{0} \quad$ frekuensi yang diobservasi

$f_{h}$ = frekuensi yang diharapkan

Analisis inferensial menggunakan

Uji statistik Non Parametrik Korelasi

Pearson untuk mengetahui hubungan antara variabel terikat (persepsi masyarakat) dan variabel bebas (tingkat pengetahuan, tingkat pendapat, dan tingkat kosmopolitan). Silaen dan Widiyono (2013) menyatakan, uji statistic pearson yaitu uji statistic yang digunakan untuk mengukur keeratan dan membuktikan hipotesis hubungan antara variabel bebas (X) dan variabel terikat (Y). Dengan rumus Korelasi Pearson sebagai berikut :

$r=\frac{n \sum x y-\left(\sum x\right)-\left(\sum y\right)}{\sqrt{\left\{n \sum x^{2}-\left(\sum x\right)^{2}\right\}}\left\{n \sum y^{2}-\left(\sum y\right)^{2}\right\}}$

Keterangan :

$\mathrm{r}=$ koefisien korelasi

$\mathrm{n}=$ banyaknya pasangan data $\mathrm{X}$ dan $\mathrm{Y}$

$\sum x=$ total jumlah dari variabel $X_{1}, X_{2}$, dan $X_{3}$

$\sum y=$ total jumlah dari variabel $\mathrm{Y}$

$\sum x^{2}=$ kuadrat dri total jumlah variabel $X_{1}, X_{2}$, dan $X_{3}$

$\sum y^{2}=$ kuadrat dari total jumlah variabel $\mathrm{Y}$

$\sum x \mathrm{y}=$ hasil perkalian dari total jumlah variabel $X_{1}, X_{2}, X_{3}$ dan $\mathrm{Y}$

Untuk menganalisis data dengan uji korelasi Pearson, peneliti menggunakan total masing-masing bobot skor data dari hasil pengamatan yang diperoleh dari variabel penelitian dalam bentuk data kualitatif yang dikuantitafkan 
menggunakan Skala Likert. Untuk menganalisis data hubungan variabel terikat dengan variabel bebas, peneliti menggunakan program SPSS versi 16.

\section{HASIL DAN PEMBAHASAN}

1. Karakteristik

Berdasarkan

Responden

Masyarakat Terhadap Dampak

konversi lahan hutan menjadi perkebunan kelapa sawit di Desa

\section{Sungai enau}

Berdasarkan hasil penelitian terkait dengan persepsi masyarakat terhadap dampak konversi lahan hutan menjadi perkebunan kelapa sawit di Desa Sungai Enau persepsi masyarakat dalam penelitian ini dikelompokkan menjadi 3 (kategori), guna lebih jelas dapat dilihat pada Tabel 2.

Tabel 2. Persepsi Masyarakat Terhadap Dampak Konversi Lahan Hutan Menjadi Perkebunan Kelapa Sawitdi Desa Sungai Enau (Community Perception of the Impact of the Conversion of Forest Land into Oil Palm Plantationsin Sungai Enau Village)

\begin{tabular}{cccc}
\hline No & Kategori & Frekuensi (Orang) & Persentase $(\%)$ \\
\hline 1 & Positif & 23 & 20,35 \\
2 & Netral & 71 & 62,83 \\
3 & Negatif & 19 & 16,81 \\
\hline & Jumlah & 113 & 100 \\
\hline
\end{tabular}

Responden yang mempunyai persepsi cenderung positif terhadap konversi lahan hutan menjadi perkebunan kelapa sawit adalah masyarakat yang beranggapan atau merasakan bahwa dengan adanya konversi lahan menjadi perkebunan kelapa sawit menciptakan lapangan pekerjaan baru bagi masyarakat setempatdan kondisi ini akan berdampak positif bagi peningkatan perekonomian masyarakat dengan manjadi buruh tani di perkebunan kelapa sawit dan terbukanya peluang usaha. Sejalan dengan penelitian Unjan et al. (2013) yang mengemukakan bahwa kelapa sawit dapat meningkatkan pendapatan dan pembangunan ekonomi. Responden yang mempunyai persepsi cenderung netral adalah masyarakat yang tidak berpihak pada salah satu persepsi positif maupun persepsi negatif terhadap konversi lahan hutan menjadi perkebunan kelapa sawit. Hal ini bisa dibuktikan dengan adanya atau tidak konversi lahan hutan menjadi perkebunan kelapa sawit, tidak memberikan pengaruh dalam aktivitas perkerjaan masyakat diluar sektor perkebunan. Masyarakat juga menyadari betapa pentingnya hutansekitar, masyarakat masih memanfaatkan hasil hutan/lahan untuk kebutuhan sehari-hari, seperti pencarian kayu bakar dan bercocok tanam yang dilakukan disekitar hutan/lahan. Responden yang mempunyai persepsi cenderung negatif adalah responden yang sudah mengetahui informasi, pengetahuan dan merasakan dampak 
dari konversi lahan hutan menjadi perkebunan kelapa sawit terhadap kondisi fisik lingkungan terutama pada musim penghujan yaitu meluapnya drainanase atau saluran parit masyarakat Desa Sungai Enau khususnya Dusun Sunge Ano. Perkembangan perkebunan sawit di Indonesia pada akhir ini menjadi salah satu titik perhatian pemerintah Indonesia karena memiliki kontribusi yang cukup terhadap perekonomian daerah maupun nasional dalam hal penyedian lapangan pekerjaan, penciptaaan nilai dan

Tabel 3. Frekuensi Responden Berdasarkan Tingkat Pengetahuan Masyarakat Desa Sungai Enau Terhadap Konversi Lahan Hutan Menjadi Perkebunan Kelapa Sawit (Frequency of Respondents Based on the Level of Knowledge of the Sungai Enau Village Community on the Conversion of Forest Land to Oil Palm Plantations)

\begin{tabular}{cccc}
\hline No & Kategori & Frekuensi (Orang) & Persentase(\%) \\
\hline 1 & Tinggi & 28 & 24,77 \\
2 & Sedang & 67 & 59,29 \\
3 & Rendah & 18 & 15,92 \\
\hline & Jumlah & 113 & 100 \\
\hline
\end{tabular}

Berdasarkan hasil pengamatan yang ditunjukkan pada Tabel 3 diperoleh frekuensi tingkat pengetahuan, masyarakat yang cenderung mempunyai tingkat pengetahuan tinggi yaitu masyarakat yang mau mencari informasi tentang dampak konversi lahan hutan menjadi perkebunan kelapa sawit mempunyai pola pikir yang baik dan mau menerima informasi dari luar, masyarakat yang cenderung mempunyai tingkat pengetahuan sedang bukan berarti masyarakat yang mempunyai pemahaman yang kurang tapi berdasarkan apa yang mereka lihat. penyedian bahan pangan (Soleman. 2010).

\section{Karakteristik Responden} Berdasarkan Tingkat Pengetahuan Masyarakat Terhadap Dampak Konversi Lahan Hutan Menjadi Perkebunan Kelapa Sawit di Desa Sungai Enau

Hasil penelitian terhadap tingkat pengetahuan dalam penelitian ini dikelompokkan dalam tiga kategori. Berdasarkan hasil perhitungan terhadap 113 responden disajikan pada Tabel 3 berikut ini. 
adalah yang memiliki persepsi yang negatif terhadap dampak konversi lahan hutan menjadi perkebun kelapa sawit pengetahuan seseorang berpengaruh terhadap pandangan seseorang jika pengetahuan masyarakat rendah ataupun sedang bukan berarti pemahaman masyarakat kurang akan tetapi masyarakat menilai apa yang masyarakat lihat.

3. Karakteristik

Responden

Berdasarkan Tingkat Pendapatan Masyarakat Terhadap Dampak Konversi Lahan Hutan Menjadi

Tabel 4. Frekuensi Responden Menurut Tingkat Pendapatan (Frequency of Respondents According to Income Level)

\begin{tabular}{ccccc}
\hline No & Pendapatan (Rp/Tahun) & Kategori & Frekuensi & Persentase (\%) \\
\hline 1 & $>35.830 .282,38$ & Tinggi & 13 & 11,50 \\
2 & $10.270 .602,58-$ & Sedang & 91 & 80,53 \\
& $35.830 .282,38$ & & & 7,96 \\
3 & $<10.270 .620,58$ & Rendah & 9 & 100 \\
\hline \multicolumn{7}{c}{ Jumlah } & & 113 &
\end{tabular}

Tingkat pendapatan yang terbanyak adalah kategori sedang yaitu $\mathrm{Rp}$. 10.270.602,58- 35.830.282.38 dengan 91 responden. Variasi tingkat pendapatan responden dikarenakan oleh sumber penghasilan yang berbeda-beda setiap responden, sumber mata pencaharian utama responden yang dominan adalah penyadap karet dan berkebun keladi dan mata pencaharian sampingan adalah karyawan sawit (tetap dan buruh) serta bertani. Hal ini menunjukan bahwa pendapatan bukan faktor dominan yang mempunyai mempengaruhi persepsi masyarakat terhadap dampak konversi lahan hutan menjadi perkebunan kelapa sawit, pemberdayaan masyarakat yang bekerja

\section{Perkebunan Kelapa Sawit di Desa Sungai Enau}

Tingkat pendapatan masyarakat Desa Sungai enau adalah dari pendapatan keseluruhan pekerjaan utama maupun pekerjaan sampingan pertahun. Responden dalam penelitian ini dikelompokkan menjadi 3 kategori. Jumlah 113 responden pada penelitian ini diperoleh frekuensi kategori responden menurut tingkat pendapatan. Terdapat pendapatan responden disajikan pada Tabel 4. 
karetnya menjadi kelapa sawit. Konversi tersebut mengakibatkan perubahan struktur pendapatan dari karet menjadi kelapa sawit. Hal tersebut mengakibatkan peningkatan pendapatan petani, total perubahan pendapatan petani sebesar 33,42\%. Perubahan pendapatan disektor on-farm sebesar 40,52\%, off-farm 24,46\% dan non-farm $25,61 \%$. Ratnawati (2014) menyatakan perubahan sikap diri seseorang tergantung dari kebutuhan hidupnya, lebih lanjutnya bahwa untuk memenuhi hidupnya seseorang harus mempunyai pendapatan dan penghasilan.

\section{Tingkat Kosmopolitan \\ Masyarakat Desa Sungai Enau \\ Terhadap Dampak Konversi

Lahan Hutan Menjadi \\ Perkebunan Sawit}

\begin{abstract}
Menurut
Rosadi

(2017)

kosmopolitan adalah konsep yang mengarahkan individu untuk berpandangan secara pengetahuan dilingkungan struktur sosialnya yakni melihat dan menilai sesuatu dari sudut pandang orang lain, Tingkat kosmopolitan merupakan suatu teori atau konsep yang dapat dipahami sebagai pengetahuan akan manusia yang mampu menerima, menyaring dan menyerap informasi yang baik sehingga terjadi perubahan pada diri mereka berdasarkan informasi tersebut. Tingkat kosmopolitan masyarakat terhadap dampak konversi lahan hutan menjadi perkebunan kelapa sawit ini di kelompokkan menjadi 3 kategori. Hasil pengamatan terhadap 113 responden disajikan dalam Tabel 5.
\end{abstract}

Tabel 5. Frekuensi Tingkat Kosmopolitan Masyarakat Desa Sungai Enau Terhadap Dampak Konversi Lahan Hutan Menjadi Perkebunan Kelapa Sawit (Frequency of Cosmopolitan Level of Sungai Enau Village Community on the Impact of the Conversion of Forest Land into Oil Palm Plantations)

\begin{tabular}{cccc}
\hline No & Kategori & Frekuensi (Orang) & Persentase $(\%)$ \\
\hline 1 & Tinggi & 15 & 13,27 \\
2 & Sedang & 79 & 69,91 \\
3 & Rendah & 19 & 16,81 \\
\hline & Jumlah & 113 & 100 \\
\hline
\end{tabular}

Tabel 6 menunjukkan bahwa dalam tingkat kosmopolitan responden di Desa Sungai enau79 responden $(69,91 \%)$ diperoleh kelompok kosmopolitan yang terbanyak. Masyarakat Desa Sungai Enau yang cenderung mempunyai tingkat kosmopolitan sedang adalah masyarakat yang memiliki pengetahuan sedang terhadap dampak konversi lahan hutan menjadi perkebunan kelapa sawit mereka memperoleh dan mencari informasi dari televisi atau radio untuk mendapatkan informasi tentang dampak konversi lahan hutan menjadi perkebunan kelapa sawit. Menurut Wahyu (2017) kosmopolitan berpengaruh terhadap persepsi masyarakat tentang keberadaan hutan di sekitar kebun kelapa sawit dengan tingkat keeratan yang cukup signifikan dimana selisih $\mathrm{C}$ max dikurang $\mathrm{C}$ sama dengan 0,0785 lebih kecil dari 1, hal ini 
dikarenakan adanya sosialisasi dari perusahaan kelapa sawit tentang bahaya kebakaran hutan dan lahan serta masyarakat desa tersebut sering mendengar dari media elektronik seperti televisi tentang manfaat hutan bagi lingkungan sehingga masyarakat Desa Lembah Hijau 1 memiliki pengetahuan dan kosmopolitan yang cukup tinggi terhadap hutan. Masyarakat Desa Sungai Enau yang cenderung mempunyai tingkat kosmopolitan sedang adalah masyarakat yang memiliki pengetahuan sedang terhadap dampak konversi lahan hutan menjadi perkebunan kelapa sawit mereka memperoleh dan mencari informasi dari televisi atau radio untuk mendapatkan informasi tentang dampak konversi lahan hutan menjadi perkebunan kelapa sawit

\section{Analisis Deskriptif}

Persepsi Masyarakat Terhadap

Dampak Konversi Lahan Hutan Menjadi Perkebunan Kelapa Sawit di Desa Sungai Enau

Persepsi masyarakat adalah penilaian atau respon masyarakat terhadap dampak konversi lahan hutan menjadi perkebunan kelapa sawit di Desa Sungai Enau dikelompokkan menjadi 3 (tiga) kategori yaitu positif, netral dan negatif. Persepsi masyarakat terhadap dampak konversi lahan hutan menjadi perkebunan kelapa sawit dianalisis dengan analisis deskriptif dengan uji statistik deskriptif chi square. Berdasarkan olahan data primer hasil pengamatan diperoleh kategori frekuensi persepsi responden terhadap dampak konversi lahan hutan menjadi perkebunan kelapa sawit di Desa Sungai Enaupada Tabel 6 berikut ini :

Tabel 6. Frekuensi Persepsi Masyarakat Terhadap Dampak Konversi Lahan Hutan Menjadi Perkebunan Kelapa Sawit di Desa Sungai Enau (Frequency of Community Perception of the Impact of the Conversion of Forest Land into Oil Palm Plantations in Sungai Enau Village)

\begin{tabular}{cccc}
\hline No & Kategori & Frekuensi (Orang) & Persentase $(\%)$ \\
\hline 1 & Positif & 23 & 20,35 \\
2 & Netral & 71 & 62,83 \\
3 & Negatif & 19 & 16,81 \\
\hline & Jumlah & 113 & 100 \\
\hline
\end{tabular}

Tabel 7. Uji Statistik deskriptif Chi Square (Descriptive Statistical Test)

\begin{tabular}{ccccccc}
\hline No & Kategori & $f 0$ & $f h$ & $(f 0-f h)$ & $(f 0-f h)^{2}$ & $(f 0-f h)^{2} / f h$ \\
\hline 1 & Positif & 23 & 37,67 & $-14,67$ & 215,11 & 5,71 \\
2 & Netral & 71 & 37,67 & 33,33 & 1111,11 & 29,50 \\
3 & Negatif & 19 & 37,67 & $-18,67$ & 348,44 & 9,25 \\
\hline & Jumlah & 113 & 113 & 0 & 1674,67 & 44,46 \\
\hline
\end{tabular}


Berdasarkan hasil data primer perhitungan Chi kuadrat (Pada Tabel 7 di atas) pada taraf signifikan 5\% dengan $\mathrm{df}=2$ menunjukkan nilai $\mathrm{X}^{2}$ hitung sebesar 44,46 dan nilai $X^{2}$ tabel $(0,05)$ sebesar 5,99.

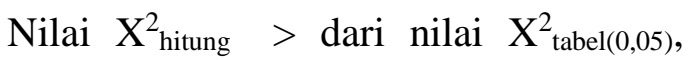
berdasarkan hasil uji analisis deskriptif disimpulkan bahwa terdapat perbedaan signifikan frekuensi persepsi masyarakat terhadap dampak konversi lahan hutan menjadi perkebunan kelapa sawit dan persepsi masyarakat cenderung netral. Berarti hipotesis yang menyatakan bahwa 71 responden (62,83\%) Masyarakat Desa Sungai Enau Kecamatan Kuala Mandor B Kabupaten Kubu Raya cenderung memiliki persepsi yang netral.Hasil olahan data primer sebagaimana diuraikan pada Tabel 8 dan hasil uji statistik deskriptif dapat di interpretasikan bahwa dari dari 113 responden penelitian sebagian 71 responden $(62,83 \%)$ masyarakat Desa Sungai Enau Kecamatan Kuala Mandor B Kabupaten Kubu Rayacenderung Netral.

Hasil wawancara dari 113 responden masyarakat yang mempunyai persepsi cenderung netral adalah responden yang mengetahui tentang dampak dari konversi lahan hutan menjadi perkebunan kelapa sawit dan merasakan dampak dari konversi lahan hutan menjadi perkebunan kelapa sawit itu sendiri. Masyarakat yang mempunyai persepsi cenderung negatif adalah responden yang telah merasakan dampak lingkungan dari konversi lahan hutan menjadi perkebunan kelapa sawit seperti aliran air parit keruh dan dangkal sehingga sering terjadi banjir. Kehadiran dan keberadaan perusahaan di tengah-tengah masyarakat juga membuka peluang munculnya konflik antara perusahaan dengan masyarakat yang dipicu oleh adanya masalah pencemaran lingkungan, masalah tanah dan lain sebagainya (Basa,2009).

Dampak positif yang dihasilkan oleh perkebunan sawit ini, terdapat pula dampak negatifnya. Keberadaan perkebunan kelapa sawit skala besar seperti sekarang ini, mengancam Kalimantan Barat sebagai satu kesatuan ekologis juga merusak keseimbangan alam dan lingkungan, seperti akar dari kelapa sawit sangat sulit untuk dibersihkan walaupun pohon sawit tersebut telah mati, namun butuh waktu bertahun-tahun agar akar dan tanah yang telah ditanami kelapa sawit dapat digunakan lagi. Selain itu tanah bekas perkebunan kelapa sawit akan menjadi gersang karena unsur-unsur hara yang ada didalam tanah telah habis (Anggun,2013). Alih fungsi lahan dapat menyebabkan menurunnya kualitas lahan, misalnya dengan cara tebang bakar (slash and burn) hal ini dikarenakan pembakaran kayu dan ranting sisa pembukaan lahan dapat mempercepat proses pencucian dan pemiskinan tanah. Merosotnya kadar bahan organik tanah akan memperburuk sifat fisik dan kimia tanah (Barchia,2009).

Analisis Inferensial

Analisis Hubungan Variabel Terikat Dan Variabel Bebas 
Guna menganalisis hubungan variabel terikat dan variabel bebas di lakukan dengan uji Korelasi Pearson yang terdiri 1 (satu) variabel terikat yaitu persepsi dan 3 (tiga) variabel bebas yaitu tingkat pengetahuan, pendapatan dan kosmopolitan. Hasil uji Korelasi Pearson variabel terikat dan variabel bebas disajikan pada Tabel 8 berikut ini.

Tabel 8. Hasil Uji Korelasi Pearson Hubungan antara Variabel Terikat dan Variabel Bebas (Pearson Correlation Test Results the Relationship Between the Dependent Variable and the Independent Variable)

\begin{tabular}{cccccc}
\hline No & Variabel & $\mathrm{N}$ & $\begin{array}{c}\text { Correlation } \\
\text { coefficient }\end{array}$ & Sig (2-Tailed) & Keterangan \\
\hline 1 & Pengetahuan & 113 & 0,283 & 0,002 & Signifikan \\
2 & Pendapatan & 113 & 0,032 & 0,737 & Tidak Signifikan \\
3 & Kosmopolitan & 113 & 0,063 & 0,505 & Tidak Signifikan \\
\hline
\end{tabular}

a. Hubungan Tingkat Pengetahuan dengan Persepsi Masyarakat Terhadap Dampak Konversi Lahan Hutan Menjadi Perkebunan Kelapa Sawit

Berdasarkan hasil Uji Korelasi Pearson sebagaimana diuraikan pada Tabel 9 diketahui adanya hubungan positif dan signifikan antara tingkat persepsidenganvariabel tingkat pengetahuandam hubungan positif dan tidak signifikan antara tingkat persepsi dengan variabel tingkat pendapatan dan kosmopolitan terhadap dampak konversi lahan hutan menjadi perkebunan kelapa sawit di Desa Sungai Enau Kecamatan Kuala Mandor B Kabupaten Kubu Raya.

Berdasarkan hasil pengamatan diketahui hasil pengamatan dari tingkat pengetahuan masyarakat terhadap dampak konversi lahan hutan menjadi perkebunan kelapa sebagian besar $(59,29 \%)$ tergolong dalam kategori sedang, sedangkan persepsi masyarakat terhadap dampak konversi lahan hutan menjadi perkebunan kelapa sawit sebagian besar $(62,83 \%)$ termasuk dalam kategori netral. Koefisien nilai korelasi sedang menunjukkan bahwa semakin sedang tingkat pengetahuan terhadap dampak konversi lahan hutan menjadi perkebunan kelapa sawit maka persepsi masyarakat cenderung netral. Ningtyas (2015) dalam penelitiannya mengatakan bahwa semakin tinggipengetahuan seseorang maka akansemakin tinggi pula persepsi positifseseorang. Sejalan dengan penelitian Yeyen et al. (2018) bahwa ada hubungan yang signifikan antara tingkat pengetahuanmasyarakat dengan persepsi masyarakat terhadap konversi lahan menjadiperkebunan kelapa sawit. Responden memiliki pengetahuan yang baik dan wawasan yang luas mempunyai pola pikir yang baik mau menerima informasi dari luar tentang dampak konversi lahan hutan menjadi perkebunan kelapa sawit. Nilai koefisien korelasi positif menunjukkan bahwa semakin positif atau tinggi 
tingkat pengetahuan masyarakat terhadap dampak konversi lahan hutan menjadi perkebunan kelapa sawit maka persepsi masyarakat akan netral.

Hasil penelitian menunjukan bahwaterdapat hubungan antara tingkat pengetahuan dengan persepsi masyarakat Desa Sungai Enau terhadap dampak konversi lahan hutan menjadi perkebunan kelapa sawit di Desa Sungai Enau Kecamatan Kuala Mandor B Kabupaten Kubu Raya diterima. Berdasarkan hasil analisis pada uji korelasi pearson, secara proporsional membuktikan bahwa terdapat hubungan antara tingkatan pengetahuan terhadap persepsi masyarakat terhadap dampak konversi lahan hutan menjadi perkebunan kelapa sawit di Desa Sungai Enau Kecamatan Kuala Mandor B Kabupaten Kubu Raya, dalam penelitian ini pengetahuan berpengaruh terhadap persepsi masyarakat tentang dampak konversi lahan hutan menjadi perkebunan kelapa sawit dengan tingkat keeratan yang cukup signifikan yaitu dengan nilai $0,002<0,05$. Hal ini dikarenakan masyarakat desa tersebut sering mendengar dari media elektronik seperti televisi tentang dampak dari konversi lahan hutan menjadi perkebunan kelapa sawit bagi lingkungan.

b. Hubungan Tingkat Pendapatan dengan Persepsi Masyarakat Desa Sungai Enau Terhadap Dampak Konversi Lahan Hutan Menjadi Perkebunan Kelapa Sawit

Berdasarkan hasil uji statistik (Uji Korelasi Pearson) antara variabel tingkat pendapatan dengan persepsi masyarakat terhadap dampak konversi lahan hutan menjadi perkebunan kelapa sawit di Desa Sungai Enau Kecamatan Kuala Mandor B Kabupaten Kubu Rayamenunjukkan bahwa terdapat hubungan positif yang tidak signifikan.

Hasil penelitian menunjukan bahwa terdapat hubungan antara tingkat pendapatan dengan persepsi masyarakat Desa Sungai Enau terhadap dampak konversi lahan hutan menjadi perkebunan kelapa sawit di Desa Sungai Enau Kecamatan Kuala Mandor B Kabupaten Kubu Raya ditolak. Berdasarkan hasil analisis uji korelasi pearson, secara proporsional membuktikan bahwa tidak terdapat hubungan antara tingkatan pendapatan terhadap persepsi dampak konversi lahan hutan menjadi perkebunan kelapa sawit di Desa Sungai Enau, dalam penelitian ini pendapatan tidak berpengaruh terhadap persepsi masyarakat tentang dampak konversi lahan hutan menjadi perkebunan kelapa sawit. Sejalan dengan penelitian Yeyen et al. (2018) bahwa terdapat hubungan yang positif tidak signifikan antara tingkat pendapatan dengan konversi lahan menjadi perkebunan kelapa sawit di Desa Nanga Tayap Kecamatan Nanga Tayap Kabupaten Ketapang. Bertentangan dengan penelitian Utamy (2017) yang mengemukakan bahwa ekspansi perkebunan mengakibatkan pendapatan petani mengalami peningkatan. Pendapatan yang dimaksud dalam penelitian ini merupakan pendapatan total individu 
responden dalam satuan terakhir yang dinominalkan dalam satuan rupiah. Berdasarkan hasil pengamatan diketahui tingkat pendapatan masyarakat sebagian besar (80,53\%) tergolong dalam kategori sedang. Hal ini menunjukkan bahwa pendapatan masyarakat tidak berpengaruh terhadap persepsi masyarakat terhadap dampak konversi lahan hutan menjadi perkebunan kelapa sawit. Hasil pengamatan dan analisis deskriptif menunjukkan bahwa konversi lahan hutan menjadi perkebunan kelapa sawit cenderung netral.

c. Hubungan Tingkat Kosmopolitan dengan Persepsi Masyarakat Desa Sungai Enau Terhadap Konversi Lahan Hutan Menjadi Perkebunan Kelapa Sawit

Berdasarkan hasil uji statistik (Uji Korelasi Pearson) menunjukkan bahwa tidak terdapat hubungan yang signifikan antara tingkat kosmopolitan dengan tingkat persepsi masyarakat terhadap dampak konversi lahan hutan menjadi perkebunan kelapa sawit di Desa Sungai Enau Kecamatan Kuala Mandor B Kabupaten Kubu Raya. Berdasarkan hasil pengamatan diketahui tingkat kosmopolitan sebagian besar $(69,91 \%)$ tergolong dalam kategori sedang, sedangkan persepsi masyarakat terhadap dampak konversi lahan hutan menjadi perkebunan kelapa sawit sebagian besar $(62,83 \%)$ cenderung netral. Bertentangan dengan penelitian Nutriawani (2017) yang menjelaskan bahwa tingkat kosmopolitan masyarakat berpengaruh positif terhadap persepsi masyarakat. Nilai korelasi positif menunjukkan bahwa semakin positif atau tinggi tingkat kosmopolitan masyarakat terhadap dampak konversi lahan hutan menjadi perkebunan kelapa sawit maka persepsi masyarakat terhadap dampak konversi lahan hutan menjadi perkebunan kelapa sawit akan cenderung netral.

\section{KESIMPULAN}

Persepsi masyarakat terhadap dampak konversi lahan hutan menjadi perkebunan kelapa sawit di Desa Sungai Enau Kecamatan Kuala Mandor B Kabupaten Kubu Raya cenderung netral yaitu dengan nilai frekuensi sebesar $62,83 \%$ dari 113 responden. Terdapat hubungan yang positif dan signifikan antara tingkat pengetahuan dengan persepsi masyarakat terhadap dampak konversi lahan hutan menjadi perkebunan kelapa sawit di Desa Sungai Enau Kecamatan Kuala Mandor B Kabupaten Kubu Raya, dan terdapat hubungan yang positif dan tidak signifikan antara tingkat kosmopolitan dan tingkat pendapatan dengan persepsi masyarakat terhadap dampak konversi lahan hutan menjadi perkebunan kelapa sawit di Desa Sungai Enau Kecamatan Kuala Mandor B Kabupaten Kubu Raya.

\section{SARAN}

Dari hasil penelitian persepsi masyarakat Desa Sungai Enau cenderung netral terhadap dampak konversi lahan hutan menjadi perkebunan kelapa sawit, oleh karena itu perlunya peningkatan kesadaran masyarakat setempat dengan memberikan penyuluhan atau sosialisasi 
supaya masyarakat lebih dapat mengetahui dampak dari konversi lahan hutan menjadi perkebunan kelapa sawit sehingga masyarakat berhenti atau mengurangi aktivitas dari konversi lahan hutan menjadi perkebunan kelapa sawit.

\section{DAFTAR PUSTAKA}

Ahmad S. 2014. Dampak Ekologi dan Lingkungan Akibat Perkebunan Sawit Skala Besar. Jurnal FKM Teknik Mesin-ITI Belitung.

Anggun A. 2013. Perkebunan Sawit di Kalimantan Barat dan Dampaknya Bagi Lingkungan. EDC (Econimic Debet Competition) BEM Fakultas Ekonomi UNTAN. Pontianak. G5

Barchia, M. F. 2009. Agroekosistem Tanah Masam. Gajah Mada University Press. Yogyakarta.

Basa AR. 2009. Dampak Sosial Keberadaan Perkebunan Pada Masyarakat. Diakses 17 Desember 2018. Artikel Cimbuak Managemen Dampak Perkebunan Pada Masyarakat.

Departermen Pendidikan dan Kebudayaan 1999, Kamus Besar Bahasa Indonesia Edisi Kedua.

Lord S dan Clay J. 2011. Environmental Impact of Oil Palm - Practial Considerations in Defining Suistainability or Impact on The Air, Land and Water. (Diakses 20 September 2019)

Murniati, Nawir, Rumboko. 2008. Rehabilitasi Hutan Indonesia. CIFOR. Bogor.

Nurhayati, Roslinda E, dan Rifanjani S. 2018. Dampak Ekspansi Pekebunan Kelapa Sawit
Terhadap Sosial Ekonomi Masyarakat Sekitar Hutan di Desa Pasak Piang Kecamatan Sungai Ambawang Kabupaten Kubu Raya. Fakultas Kehutanan Universitas Tanjungpura. Pontianak Jurnal Hutan Lestari. Vol.6 (4): 1039-1049

Nutriwani R, Bachrun N, Joko N. 2017.Sikap Masyarakat Dusun PasirLaut Terhadap Keberadaan HutanMangrove Di Dusun Pasir LautKecamatan Mempawah HilirKabupaten Mempawah. Jurnal Hutan Lestari Vol 5 No 2.

Silaen S, Widiyono. 2013. Metodologi Penelitian Sosial Untuk Penulisan Skripsi Dan Tesis. Jakarta: In Media.

Soleman, I. 2010. Analisis Dampak PIR Kelapa Sawit Terhadap Kesejahteraan Masyarakat Sekitar Di Kabupaten Manokwari. Program Magister Pslp Ppsub Issn.0852-5426. 18(02). April 2010. Manokwari. Di Akses 3 Agustus 2019

Sugiyono. 2011. Metode Penelitian Pendidikan (pendekatan kuantitatif, kualitatif, dan R\&D). Alfabeta, Bandung

Syahza, Almasdi. 2011. Percepatan Ekonomi Pedesaan Melalui Pembangunan Perkebunan Kelapa Sawit. Jurnal Ekonomi Pembangunan. Volume 12, Nomor 2, Desember 2011, hal 297-310.

Utami R, Putri KIE dan Ekayani M. 2017. Dampak Ekonomi dan Lingkungan Ekspansi Perkebunan Kelapa Sawit Kabupaten Tanjung Jabung. Jambi. Jurnal Ilmu Pertanian

Indonesia. 
www.://journal.ipb.ac.id/index.ph p/JIPI (Diakses 15 Desember 2018)

Wahyu S, Thamrin E dan Idham M. 2017. Persepsi Masyarakat Terhadap Keberadaan Hutan Disekitar Kebun Kelapa Sawit Desa Lembah Hijau 1 Kecamatan Nanga Tayap Kabupaten Ketapang. Fakultas Kehutanan. Universitas Tanjungpura. Jurnal Hutan Lestari. Vol 5(3). 680-687. Diakses 20 Januari 2019.

Yeyen, Muin S dan Fahrizal. 2018. Persepsi Masyarakat Terhadap Konversi Lahan Menjadi Perkebunan Kelapa Sawit Di Desa Nanga Tayap Kecamatan Nanga Tayap Kabupaten Ketapang. Fakultas Kehutanan. Universitas Tanjungpura. Jurnal Hutan Lestari. Vol 6(4). 742-741. Diakses 11 Januari 2019 